УДК 101.1:316.422:330.123

\title{
БЛАГО ЧЕЛОВЕКА В МИРЕ ИННОВАЦИЙ: К МЕТОДОЛОГИИ ОБОСНОВАНИЯ КРИТЕРИЕВ ИДЕНТИФИКАЦИИ
}

\author{
Ланкин Вадим Геннадьевич, \\ lankinvg@mail.ru \\ Галмагова Гезаль Мамедрасуловна, \\ g.m.gm@mail.ru \\ Томский архитектурно-строительный университет, \\ Россия, 634003, г. Томск, пл. Соляная, 2.
}

\begin{abstract}
Ланкин Вадим Геннадьевич, доктор философских наук, профессор кафедры философии и истории общеобразовательного факультета Томского архитектурно-строительного университета.
\end{abstract}

Галмагова Гезаль Мамедрасуловна, аспирантка кафедры философии и истории общеобразовательного факультета Томского архитектурно-строительного университета.

В статье рассматриваются методологические подходы при построении антропологии инновации как сферы знания, необходимой сегодня для объективной оценки инноваций и проектов в области социальных технологий, имеющих существенное воздействие на человека. Цель исследования - построение концептуальных оснований для осмысления и оценки социальных и технологических инноваций в их значении для человеческого бытия. Это предполагает ответ на вопрос «что есть благо для человека в условиях перманентных и тотальных инновационных процессов?». Методология предлагаемого подхода основывается на понимании человека как смыслообразующего центра в открытом мире-событии и как метасистемы по отношению к системам общества и технологий. Варианты логики инновационных изменений рассмотрены в ключе таких понятий, как интеграция, эволюция, трансгрессия, инволюция. Результаты работы отражают положение, что критерии блага человека в условиях широких непрерывных инноваций могут строиться на объективноантропологической основе, а не на субъективно-этической, что ключевые ориентиры определения позитивной значимости изменений человеческой действительности - это идентичность, развитие, жизнь и безопасность. В статье дается краткая оценка практической значимости ее теоретических результатов, связанная с возможностью уточнения постановки целей социальной рефлексии, экспертной оценки и контроля инноваций, способных существенно преобразовывать жизнь человека, с конкретизацией и коррекцией инструментария гуманитарной экспертизы значимых инноваций в их направленности на благо человека и его развитие.

Ключевые слова: Инноватика, антропология, благо, технологии, переосмысление, эволюция, идентичность, трансгрессия, инволющия, интеграция, гуманитарная экспертиза.

Современная ситуация в целом такова, что мощный инновационный поток затрагивает разные сферы жизни - от экономики и информационной коммуникации до способов социального взаимодействия и формирования сознания людей. В этих условиях человеческая действительность рискует утратить статус основной системы координат для соизмерения социально-технологической активности. Возникает проблема системно-смыслового статуса человеческой действительности: человек - по преимуществу предмет воздействия и преобразований или он по преимуществу субъект, т. е. смыслообразующий центр всей системы. Либо он подлежит регулированию и реконструированию в критериях эффективности, удобства, успешности, управляемости, социальной 
релевантности и технологической компетентности, либо он сам все же выступает как источник и основание критериев осмысления системы его активности - критериев его человеческой аутентичности, смысловой идентичности и развития в качестве субъекта. Другими словами, таких критериев, которые нельзя редуцировать к социально и технологически значимым качествам и которые, таким образом, уместно назвать собственно гуманитарными.

Несмотря на то, что сегодня доминирует идеология инновационности, инновации нельзя априори считать маркером абсолютной ценности. Напротив, они должны оцениваться с позиции неких более высоких и фундаментальных критериев. Технологическая и экономическая сферы, представляя собой инстанции инструментария и инициативы в социальных процессах, не могут представить исчерпывающие основания осмысления векторов обновления и развития человека как существа и общества как системы взаимодействия людей. Требуются средства осмысления, базирующиеся на понимании общества как развивающегося целого и интерпретации человека как существа, обеспечивающего это развитие. При этом гуманитарно-антропологическое основание такого осмысления более фундаментально, чем основание социальное.

Проблематика гуманитарного подхода в определении значения инноваций сегоднядалека от разрешения. Требуется не просто учет «человеческого фактора», «человеческого капитала», «прав человека» или свойств homo innovaticus (человека, пластично встроенного в процессы экономических инноваций) - именно эти концепты являются ключевыми в современном дискурсе инноватики и гуманитарной экспертизы. Необходимо исходить из того, что весь инновационный спектр - от экономических, технических до культуросозидательных практик - будет требовать оценочной рефлексии и опережающего осмысления вероятных изменений в системе общества как целого, и прежде всего в системе существования и развития человека как такового. Для этого потребуется систематически построенная теория человека как субъекта и одновременно предмета инноваций. Только на этой основе возможны необходимая сегодня социуму перспективно опережающая оценочность и регулируемость инновационных процессов. Именно так появится возможность адекватно ориентироваться в нарастающем потоке инноваций - как минимум для того, чтобы иметь шансы выбора необходимых желательных изменений, а не оказаться (оставаться) в плену линейных трендов технического нарастания и социально-технологического продвижения. Иначе человечеству в обозримой перспективе угрожает расчеловечивание не только в таком виде, как это эксплицируется в идеологии постгуманизма/трансгуманизма, но и в продолжении ряда непосредственно наблюдаемых процессов, обусловливающих деградацию некоторых важных человеческих способностей.

При этом можно определить объективный проблемный контекст: нарастание изменений в сфере человеческого существования - в области человеческих способностей, условий и перспектив их развития под действием социальных и технологических инноваций - при недостаточности и отставании средств распознания, оценки значимости и социального контроля таких изменений.

Можно сказать, что существует острая проблема - отсутствие объективных фундаментально обоснованных и гарантированно проверенных критериев выделения и оценки существенных изменений, порогов и параметров риска человеческого существования в условиях нарастания инновационных процессов. Это проблема неясности понимания, что есть благо для человека в условиях перманентных и тотальных инновационных процессов. 
Эту проблему можно выразить в виде ряда вопросов. Насколько изменчива человеческая природа под действием социальных и технологических инноваций? Каковы направления и факторы позитивных и негативных действий и пороги риска в ходе и в перспективе такого рода изменений? Иными словами, что есть благо для человека в условиях меняющегося мира и инновационно трансформирующейся цивилизации и каким способом его можно идентифицировать условиях технологического прогресса? Каковы концептуальные ориентиры и объективные критерии определения значимости инновационных изменений в гуманитарном измерении?

При решении данной проблемы имеют особое значение обретение четких - необходимых, достаточных, объективных и прочных - оснований при осмыслении и оценке социальных и технологических инноваций, подразумевающих существенные изменения в области человеческого бытия. Таким образом речь идет об основаниях на уровне антропологии инновации. Это сфера изучения человека в поле инноваций в аспектах динамики способностей, возможности изменений и критериев гуманитарной оценки системных трансформаций.

Обозначенная проблематика затрагивается в работах, направленных на постановку вопроса философского обоснования инноватики [1], а также статьях, посвященных проблематизции гуманитарного аспекта в области инноватики [2], включая факторы человеческих ценностей и этической ответственности в социальных инновациях [3]. В этом же ключе можно рассматривать и идеи деантропологизации $[4,5]$ и «техногуманизма»[6], представляющие собой философское осмысление актуальной трансформации человеческой действительности. Близкий аспект - анализ того, как социальные, информационные технологии влияют на антропологическую методологию и определяют то, что уместно и важно выделить в человеческой действительности в качестве самого существенного. Другими словами, это аспект определения того, в чем состоит существо человеческих способностей и как информационные технологии при этом задают векторы развития человеческих способностей, т. е. играют антропологически конструирующую роль [7-9].

Контекст данной проблематики включает и целый ряд тем, в рамках которых так или иначе рассматриваются аспекты изменчивости человеческого существа и преобразуемости человеческой природы [10], оценки идей постгуманизма[11], проблемы гуманитарной экспертизы инноваций [12-14], а также соотношения человеческого и искусственного интеллекта [15-18],НБИК-конвергенции [19], «нейроэтики» [20], вопросов изменений и реформ в образовании, затрагивающих трансформацию человеческой действительности [21-23]. Но надо признать, что фундаментального и в то же время многоаспектного раскрытия проблематики антропологии инновации до сих пор не существует.

Методология построения антропологической теории инноватики предполагает следующий подход: человек должен быть определен не как существо с присущей ему природой и не как деятельная инстанция с присущей ей свободой воображения, творческого целеполагания или спонтанности в мотивации. И то, и другое - крайности (первый подход ограничивает и цементирует заданность человеческого существа, второй рассматривает человека не просто как субъект, но и как предмет преобразования, и многообразие такого преобразования представляется принципиально неограниченным). Человек должен быть представлен в логике и онтологии конструктивного события и определен как открытое событие, имеющее, однако, свою событийную структуру. Эта структура определяет ключевую способность образовывать новые смыслы, предполагает варианты развертывания (человеческое событие вариантно), но она и указывает на 
направления конструктивных/деструктивных изменений. Человеческое событие - это процесс ортогенеза смыслообразущей субъектности. Раскрытие такой структуры позволяет выйти из тупика «свободы без берегов» и «веера возможностей» и эксплицировать своеобразную истину человеческого - соответствие направленности преобразований такому развитию, при котором не теряются, а усиливаются способности смыслообразования, утверждается, а не ослабевает субъектность человеческого существа.

Такой подход позволит выйти за рамки не только дилеммы природа/свобода, но и дилеммы консервация/инновация (традиция/эволюция). Развитие и инноватика имманентны человеческому бытию, но критериальная основа конструктивности такого развития - продвижение именно и прежде всего смыслообразующей способности. В связи с этим методология оценки инноваций в гуманитарном аспекте касается не только новых действий и небывалых последствий, но новых смыслов - оценки по основанию их соответствия росту и развитию смыслообразущих способностей человека.

При понимании человека как смыслообразующей, переосмысляющей инстанции бытия, с одной стороны, открывается возможность обоснования (развития) способностей homo innovaticus, что выводит действительность человеческого за рамки природной и традиционно-культурной заданности, а с другой стороны - устанавливает четкие критерии идентичности человеческого существа и направленности его развития.

Важный методологический ориентир, позволяющий мыслить человеческое существо именно так, - это принципиальное положение, что человек - не «среда формирования социальных систем», а метасистема по отношению к системе общества (системе взаимодействия людей). И одновременно способность человека к переосмыслению это не средство для адаптации при освоении отрывающихся технических и социальнотехнологических возможностей, а общее и базовое основание как для культуры - системы ценностей и норм, так и для техники (технологии) - системы адаптирующего преобразования человеком природной и социальной среды.

Чтобы осмыслить инновационные процессы в их антропологическом значении, надо принципиальным и систематическим образом представить варианты и модусы изменчивости как таковой, которые, с одной стороны, позволяют дифференцированно рассматривать происходящие и возможные новации, а с другой - анализировать их действие по отношению к системе человеческих свойств. Это мы и сделаем далее через системную координацию ряда основных понятий, отражающих природу и характер возможных качественных изменений.

C XVIIIи до начала XX вв. господствовала идея линейного прогресса; именно она призвана была отображать логику изменений в социально-гуманитарной сфере. В философской системе Г. Гегеля описание развития приобрело более сложную, «спиралевидную» конфигурацию. Но поскольку Г. Гегель не рассматривал внешний характер взаимодействий и предполагал, что любые противоположности имеют внутренний характер (получены путем деления потенциально противоречивого целого), то такой фактор качественных изменений, как интеграция разных и тем более разнородных начал, его диалектическая логика не включала. Этот фактор был фундаментальным образом учтен только в рамках концепции синергетики. Понятие эволюции, распространившееся с середины XIX в., в отечественной философии сопоставлялось обычно с понятием революции. Кстати, тот и другой концепт, выражавшие различие в динамике изменений постепенных или скачкообразных, - отражали все ту же логику прогресса.

Между тем, прогресс это не абсолютное понятие, а относительное. И соответственно действие этого понятия ограничено. Нельзя сказать, что имеет место продвижение (вперед), если не предполагать цели на карте местности или хотя бы ценностно- 
го горизонта за ее краем (например, в виде желанной утопии).Относительность понятия прогресса можно выразить и через параметры нарастания в направлении уже имеющихся тенденций. Здесь имеет силу фактор кумулятивности - накапливаемости ценных изменений. В феномене технического прогресса этот фактор очевиден: новые приспособления всегда строятся на основе или на элементах ранее созданных приспособлений. Но вот говорить о прогрессе в науке в таком ключе уже трудно - этому мешают экспликации Т. Куна и догадки П. Фейерабенда. Тем более трудно говорить о прогрессе в искусстве с присущей его исторической динамике линией подъемов, взлетов и относительного упадка.

Чтобы четко и системно представить себе вариантность изменений в аспектах их природы и направленности, надо сопоставить в единой системе координат четыре основных и принципиальных понятия: интеграция, эволюция, трансгрессия, инволющия.

Интеграџия это объединение свойств структур, ранее бывших отдельными, за счет чего происходит нарастание новых качеств целого. Это логика прививки растения, симбиоза в формировании биологических форм, заимствований и насаждений в истории культуры. Интеграция не является безусловным залогом развития как нарастания новых свойств. И социальная интеграция не является абсолютным критерием гуманитарной ценности: человек может деградировать в слишком усовершенствованном обществе, становясь всего лишь, по Н. Луману, «средой для формирования социальных систем».

Эволюция (развитие в строгом смысле) - это нарастание новых свойств системы на основе прежних ее свойств. Это означает, что сохраняется нечто принципиально важное именно в качестве неуничтожимой основы роста. Это нечто следует назвать идентичностью. Эволюция может происходить (и может быть мыслима) только на основе идентичности той структуры, которая таким образом развивается. Именно это обеспечивает умножение свойств - усложнение, совершенствование. Опираясь на эту логику трудно поверить, что любая инновация хороша в гуманитарном измерении. Если человек теряет при этом идентичность, выраженную в виде неких существенных, принципиальных свойств, - то это эффект объективной деструкции - в лучшем случае инволюция, но никак не развитие.

Понятие трансгрессии в данной системе сопоставлений выражает выход или даже переход за рамки самого себя - продвижение за пределы возможного себя. Логика такого выхода отлична от логики эволюции: новые свойства появляются за счет отрицания прежних свойств. Трансгрессия - это изменение с преодолением идентичности. Такого рода переходы обычно вызывают проблему общего понятия: можно ли, например, к некойновой арт-практике применить известное понятие искусства? В связи с этим понятие «трансгуманизм» камуфлирует значение трансгрессии как перехода системы на другие основания, как утрату идентичности. Откровенно такой переход выражает понятие «постгуманизм». Логика изменений такого рода такова, что одни свойства добавляются, другие исчезают - так, что суммарный результат не гарантированно положительный. Поэтому трансгрессия и связана зачастую не с усложнением и совершенствованием, а с упрощением и деградацией.

С эффектом деградационной утраты связано понятие инволюиии. Оно означает упрощение, уменьшение количества свойств системы. Такое имеет место главным образом в связи с тем, что данная структура как подсистема включается в систему большего порядка, которая постепенно отбирает на свой системный уровень многие функции входящей в нее структуры. Например, человек в обществе полной обеспеченности, равно как и в комфортной среде эффективной техники, теряет потребность, а вслед за 
ней, должно быть, и способность, «напрягаться» телом и умом. Ему, к примеру, не надо работать и можно вообще не думать, - если развернуть эту логику в пределе. Этот вариант логики изменений связан и с общей рамкой интегращии: интеграция человека в общество умных машин с доминантой машинного «суперинтеллекта» поведет, скорее всего, к инволюционной деградации человека, поэтому такие прогнозы и проекты при всей их технической прогрессивности можно оценить в антропологическом измерении как негативные.

Вывод, который можно сделать из данной системы понятий, объясняющих вариантную логику инновационных изменений, таков: позитивное значение в антропологическом измерении могут иметь только изменения, означающие нарастание свойств человека в модусе развития его способностей при опоре на основания человеческой идентичности. Под идентичностью при этом надо понимать совокупность стержневых свойств человеческого существа, среди которых наряду с жизнью (и соответственно ценностью ее качества и безопасности) надо поставить сознание как способность образовывать новые смыслы и его культурно-смысловую укорененность. Развитие при этом надо понимать прежде всего как увеличение возможностей человеческого мышления, познания и нравственной саморефлексии - как форм активизации процессов сознаниясмыслообразования. Равно как развитие надо понимать и как увеличение возможностей человеческой жизни и безопасности, что связано не только с умножением технологий, но и с уточнением норм и ценностей культуры. Все прочее может модифицироваться, включая человеческое тело и внесознательные аспекты человеческой психики. Но такая модификации должна быть скоординирована в рамках критериев позитивного влияния на сформулированные выше принципы идентичности и развития.

Надо обратить внимание: то, что представляют собой критерии блага в перспективе антропологии инновации, - это критерии объективно-онтологические. Они исходят не из метафизического понимания человека и мира, а из интерпретации человека как смыслообразующего события в открытом мире-событии. Почему мы вынуждены возвращаться к онтологической трактовке понятия блага после четырех столетий его субъективно-эвдемонической, субъективно-этической трактовки? Дело в том, что, вопервых, человек сегодня - не только субъект, но и объект техники и технологий, т. е. как субъективность он не аутентичен или аутентичен не в полной мере. Он все больше агент, а не актор и тем более не автор (не субъект). Во-вторых, динамика инновационных трансформаций такова, что их приходится рассматривать как автономную силу, похожую по своей значимости на силы природы - силу уже не столько субъективно мотивированного порядка, сколько объективно самовоспроизводящегося. Человек становится объектом технологий, а техника становится агентом социума, и эта специфическая инверсия востребует включение объективно-антропологического осмысления блага человека.

Объективным онтологическим критерием блага человека (и блага вообще) может выступить понятие конструктивности: благо - это созидательная тенденция и интенция, зло - деструктивная (прямо или опосредованно, намеренно или как неучтенный эпифеномен). Созидательная тенденция в отношении человеческого существования это упрочение и усиление субъектного статуса человека, развитие соответствующих этому статусу способностей. Деструктивная тенденция - это лишение человека такого статуса, ослабление его субъектных смыслообразующих способностей, в той или иной мере превращение человека в «недочеловека».

На этой основе появляется возможность соизмерения существовавших, действительных и возможных (появляющихся конструктивных) связей в одной системе коор- 
динат - при учете разноуровневости и, соответственно, неравнозначности этих связей в системе человеческого бытия (события). Другими словами, открывается возможность сопоставления новообразованной структурности со структурностью, разрушаемой и деформируемой при данном переключении связей. Таким образом, здесь применим критерий конструктивности, тесно связанный с критерием интегративности связей, при том, что конструктивность понимается как общий показатель накопления взаимоподдерживающих связей, образующих сложную систему, а интегративность - как расширение системы связей с охватом ею разных уровней и сфер.

Для того чтобы человеческое измерение могло стать действительной критериальной основой осмысления и оценки социально-технологического развития, система координат должна обрести двухуровневость: человеческая действительность должна мыслиться (предстать) как смысловая метасистема по отношению к системам социального взаимодействия технологического приспособления, которые, в свою очередь, предстанут как подсистемы, требующие контроля их динамики со стороны метасистемы гуманитарного порядка. Человек должен предстать не столько как предмет конструирования в логике подстраивания под динамику перемен, сколько как субъект, обладающий способностями смыслового созидания и интенсивного саморазвития. И при этом человеческая действительность, поскольку она действительно изменяема технологически, останется предметом конструирования, но одновременно и оценки его направленности, обнаружения скрытых рисков, побочных действий, показаний и противопоказаний. Пошаговое конструирование и системная оценка по критерию итоговой конструктивности будут неразрывным целым - системой человеческого самоопределении и регулирования в мире инноваций.

Суммируя основные выводы предложенного рассуждения, можно сделать ряд кратких заключений.

Человеческое бытие это одновременно присутствие (идентичность и самоутверждение) и появление (переосмысление и самообновление). Поэтому оценка его оптимальных условий должна основываться как на факторе (критерии) идентичности, и соответственно, соотнесении с (некоторым) эталоном, так и на факторе обновления и развития, и соответственно, с мерой конструктивности новообразованных структур в сравнении с преобразуемыми старыми. Считать же фактор обновления, новизны как таковой самоценным при этом, очевидно, нельзя. Вопреки установкам современной инноватики новое отнюдь не всегда лучше старого - именно определение этого соотношения и является предметом анализа и оценки.

При этом основные объективные критерии блага человека в мире инноваций - это в аспекте биологической природы человека жизнь и безопасность, а в аспекте природы человеческой субъектности - это критерий идентичности человека как носителя способности смыслообразования, критерий развития, который обретает силу только на основе культурно-смысловой идентичности. Действие этих критериев означает приоритет сохранения и обретения эффективных средств развития мышления и познания и утверждения доминирующего положения человека-субъекта по отношению к создаваемой им техники и организуемому им обществу. Появление новых способностей, в частности, в логике идей трансгуманизма, может мыслиться только в соотнесении с такими приоритетами.

Данный подход строится на признании возможности обретения методологически достоверных системно выстроенных оснований квалификации изменчивости человеческого существа при опоре на методологию понимания человеческой действительности как открытого события, основывающегося на способности к переосмыслению бытия и 
при этом конструктивно направленного на сохранение и развитие именно этой способности.

Реализация такого подхода возможна на основе человеческой действительности как смыслообразующей метасистемы социального развития и понимания человека не как метафизической данности (заданности), а как конструктивного события смыслообразования, в котором критерием конструктивности как раз и выступает уровень смысловой целостности и интегративности человеческого существования, который достигается благодаря новым условиям осуществления человеческой деятельности, возникающим благодаря технологическим и социальным инновациям.

Тем самым открывается возможность создать методологическую и теоретическую основу для формулирования философско-антропологических принципов и выделения гуманитарных критериев оценки инноваций, ведущих к трансформации человеческой действительности. А также возникает перспектива создания теории изменчивости человеческого существа на основе технологических и социальных нововведений и определения блага человека в этих условиях - теории, которую верно было бы назвать антропологией инновации.

В практическом плане это позволяет дать методологически четкое обоснование принципов и постановку целей социальной рефлексии, экспертной оценки и контроля инноваций, способных существенно преобразовывать жизнь человека. Могут быть выработаны конкретные средства оценки инновационных процессов технологического и социального характера с позиций сформулированной теории антропологии инновации. Приложения этой теории будут применимы для оценки, экспертизы и прогнозирования по отношению к уже текущим процессам, к реализуемым и обсуждаемым проектам, имеющим существенное инновационное значение. В частности, они позволяют формулировать условия оптимума и выявлять зоны риска для человеческого существования в условиях его существенного изменения как в результате актуальных инноваций, так и в проекции возможных социальных и технологических. Прежде всего подобные зоны риска могут быть маркированы в таких сферах значимых социально-технологических преобразований, как информационная среда, среда коммуникационных возможностей, условия автокоммуникации (смысловой рефлексии), психологические процессы и состояния (восприятие, мотивация, адаптация), среда социальных взаимодействий, контекст повседневности. Это позволит конкретизировать задачи и инструментарий гуманитарной экспертизы проектов и процессов инновационного изменения человеческого существования в таких предметных сферах, как конструирование техногенной среды, реформирование системы образования, развитие коммуникаций, мышления и поведения на основе IT, в том числе социальных технологий манипулятивного воздействия на человеческое сознание и мотивацию. Все это откроет возможность усовершенствовать инструментарий осуществления гуманитарной экспертизы и прогнозирования, в том числе и разрабатывать алгоритмы применения такой экспертизы для оценки технологического изменения природной, техногенной и информационной среды человеческого существования, включая сферы социальных технологий, предметом или косвенным эффектом которых являются изменения человека как субъекта деятельности.

\section{СПИСОК ЛИТЕРАТУРЫ}

1. Егоркин В.Г. Философия инноваций // Terra humana. URL: http://www.terrahumana.ru/arhiv/06_01/06_01_03.pdf (дата обращения: 22.10.2019).

2. Другова Е.А. Инноватика в поиске нового гуманитарного содержания: Онтология, аксиология, методология // Вестник Томского государственного университета. Философия. Социология. Политология. - 2013. - № 1 (21) - С. 5-19. 
3. Sarkki S., Ficko A., Miller D. Human values as catalysts and consequences of social innovations. // Forest policy and economics. - 2019. - V. 104. - P. 33-44.

4. Гуревич П.С. Новые темы философской антропологии (очерки). Очерк 1. Феномен деантропологизации человека // Личность. Культура. Общество. - 2009. - Т. 11. - № 1 (46-47). - С. 236-250.

5. Черных С.И., Паршиков В.И. «Новая пайдейя», или останется ли человек человеком? - Новосибирск: Золотой колос, 2018. - 142 с.

6. Эпштейн М.Н. Техногуманизм: техника как творческое самопреодоление человека // Человек: образ и сущность. - 2014. - № 1 (25). - С. 137-155.

7. Ланкин В.Г. Человек как конструкт информационно-коммуникативных технологий // Конструирование человека: сборник трудов Всероссийской научной конференции. - Томск: Изд-во ТГПУ, 2007. C. 215-220.

8. Ланкин В.Г. Человек как предмет техники: Возможности и проблемы трансгуманизма // Молодежь, наука, технологии: новые идеи и перспективы: III Международная научная конференция (МНТ2016). - Томск: Изд-во ТГАСУ, 2016. - С. 849-860.

9. Lankin V.G., Kokarevich M.N., Lysunets T.B. Man as Matter of Engineering: Ethical, Epistemological and Technological Boundaries of Transhumanism // Responsible Research and Innovation: International Conference. - Tomsk, 7-10 November 2016. - V. XXVI. - P. 497-505.

10. Habermas J. The future of human nature. - Cambridge: Polity press, 2003. - $136 \mathrm{p}$.

11. Фукуяма Ф. Наше постчеловеческое будущее. Последствия биотехнологической революции. - М.: Изд-во АСТ, 2004. - 349 с.

12. Lankin V.G., Kokarevich M.N., Lysunets T.B. Humanitarian expertise as a tool for creating the image of well-being future // International Scientific Symposium on Lifelong Wellbeing in the World. - Tomsk, 2018 - V. XXXVIII. - P. 294-304.

13. Ланкин В.Г., Селиванов С.А. Гуманитарная экспертиза как инструмент формирования образа благополучного будущего // Вестник науки Сибири. - 2018. - № 1 (28). - С. 88-101.

14. Моисеева А.П., Ланкин В.Г., Кондратьева И.В. Социальная инженерия в контексте трансдисциплинарности. - Томск: Изд-во ТПУ, 2012. - 240 с.

15. Kowert W. The Foreseeability of human artificial intelligence interactions // Texas law review. - 2017. V. 96. - Iss. 1. - P. 181-204.

16. Lichtenthaler U. Substitute or Synthesis? The Interplay between human and artificial intelligence. // Research-technology management. - 2018. - V. 61. - Iss. 5. - P. 12-14.

17. Gobet F., Sala G. How artificial intelligence can help us understand human creativity // Frontiers in psychology. - 2019. - V. 10. - Article number 1401. DOI: 10.3389/fpsyg.2019.01401

18. Livingston S., Risse M. The future impact of artificial intelligence on humans and human rights // Ethics \& international affairs. - 2019. - V. 33. - Iss. 2. - P. 141-158.

19. Van Est R. Intimate technology: the battle for our body and behavior. 2014. - 86 p. URL: https://pure.tue.nl/ws/portalfiles/portal/3957297/608649605251186.pdf (дата обращения: 22.10.2019).

20. Salles A., Evers K., Farisco M. Neuroethics and philosophy in responsible research and innovation: the case of the human brain project // Neuroethic. - 2019. - V. 12. - Iss. 2. - P. 201-211.

21. Ланкин В.Г. Между личностью и профессией. Идеи и проблемы компетентностного подхода и активизирующих технологий в высшем образовании // Вестник ТГПУ. - 2012. - Вып. 11 (126). - С. 9-14.

22. Yablonskyi A. Educational institution environment as the subject of humanitarian psychological expertise // Science and education. - 2016. - Iss. 11. - P. 85-90.

23. Ланкин В.Г. Модульность образования и целостность человека: к критериям экспертизы гуманитарных практик // Вестник науки Сибири. - 2012. - № 1 (2). - С. 203-209.

Поступила 25.10.2019 2. 


\title{
GOOD OF HUMAN IN THE WORLD OF INNOVATIONS: TOWARDS THE METHODOLOGY OF JUSTIFICATION OF IDENTIFICATION CRITERIA
}

\author{
Vadim G. Lankin, \\ lankinvg@mail.ru \\ Gezal M. Galmagova, \\ g.m.gm@mail.ru
}
Tomsk State University of Architecture and Building, 2, Solyanaya square, 634003, Tomsk, Russia.

\begin{abstract}
Vadim G. Lankin, Dr. Sc., professor, Tomsk State University of Architecture and Building.
Gezal M. Galmagova, graduate student, Tomsk State University of Architecture and Building.
\end{abstract}

The article discusses methodological approaches to the construction of the anthropology of innovation as a sphere of knowledge for objective assessment of innovations and projects in the field of social technologies that have a significant impact on humans. The aim of this article is to build conceptual foundations for understanding and evaluating social and technological innovations in their significance for human life. What is good for a person in the conditions of permanent and total innovative processes - this question is taken in the issue. The methodology of the proposed approach is based on understanding of a person as a meaningforming event in the open world-event and as a metasystem in relation to systems of society and technology. The results of the work reflect the position that the criteria for the benefit of man under conditions of widespread continuous innovation can be built on an objective-anthropological basis, that the key guidelines for determining the positive significance of changes in human reality are identity, development, life and security. The article gives an assessment of practical significance of its theoretical results, related to the possibility of clarifying the aims of social reflection, expert assessment and control of innovations in its humanitarian significant, to concretization and correction of the humanitarian expertise tools.

Key words: Innovation, anthropology, good, technology, rethinking, evolution, identity, transgression, involution, integration, humanitarian expertise.

\section{REFRRENCES}

1. Egorkin V.D. Filosifiya innovatsii [The Philosophy of innovations]. Terra humana. Available at: http://www.terrahumana.ru/arhiv/06_01/06_01_03.pdf (accessed 22 October 2019).

2. Drugova E.A. Innovatika v poiske novogo gumanitarnogo soderzhaniya: ontologiya, aksiologiya, metodologiya [Innovation in the search for new humanitarian content: ontology, axiology, methodology]. Tomsk State University Journal of Philosophy, Sociology and Political Science, 2013, no. 1 (21), pp. 5-19.

3. Sarkki S., Ficko A., Miller D. Human values as catalysts and consequences of social innovations. Forest policy and economics, 2019, vol. 104, pp. 33-44.

4. Gurevich P.S. Novye temy filosofskoy antropologii. Ocherk 1. Fenomen deantropologizatsii cheloveka [New topics of philosophical anthropology. Essay 1. The phenomenon of human deanthropologization]. Lichnost. Kultura. Obshchestvo, 2009, vol. 11, no. 1 (46-47), pp. 236-250.

5. Chernykh S.I., Parshikov V.I. «Novaya paideya», iliostanetsya li chelovekchelovekom? [«The New Paideia», or will man remain human?]. Novosibirsk, Zolotoykolos Publ., 2018. 142 p.

6. Epshteyn M.N. Tekhnogumanizm kak tvorcheskoe samopreodolenie cheloveka [Techno-humanism: technology as creative self-overcoming of a man]. Chelovek: obraz i sushchnost, 2014, no. 1 (25), pp. 137-155.

7. Lankin V.G. Chelovek kak konstrukt informatsionnykh tehnologiy [Man as a construct of information and communication technologies]. Sbornik trudov Vserossiyskoy nauchnoy konferentsii. Konstruirovanie che- 
loveka [Human Design. Proc. of the All-Russian Scientific Conference]. Tomsk, TSPU Publ., 2007. pp. $215-220$.

8. Lankin V.G. Chelovek kak predmet tekhniki: vozmozhnosti i problemy transgumanizma [Human as an object of technology: opportunities and problems of transhumanism]. III Mezhdunarodnaya nauchnaya konferentsiya. Molodezh, nauka, tekhnologii: novye idei i perspektivy (MNT-2016) [III International Scientific Conference. Youth, Science, Technology: New Ideas and Prospects]. Tomsk, TSUAB Publ., 2016. pp. 849-860.

9. Lankin V.G., Kokarevich M.N., Lysunets T.B. Man as Matter of Engineering: Ethical, Epistemological and Technological Boundaries of Transhumanism. International Conference. Responsible Research and Innovation. Tomsk, 7-10 November 2016. Vol. XXVI, pp. 497-505.

10. Habermas J. The future of human nature. Cambridge, Polity press, 2003. $136 \mathrm{p}$.

11. Fukuyama F. Nashe postchelovecheskoe budushchee. Posledstviya biotekhnologicheskoy revolyutsii [Our posthuman future. The consequences of the biotechnological revolution]. Moscow, AST Publ., 2004. 349 p.

12. Lankin V.G., Kokarevich M.N., Lysunets T.B. Humanitarian expertise as a tool for creating the image of well-being future. IV International Scientific Symposium on Lifelong Wellbeing in the World. Tomsk, 2017. Vol. XXXVIII, pp. 294-304.

13. Lankin V.G., Selivanov S.A. Humanitarian expertise as a tool for creation the image of well-being future. Siberian Journal of Science, 2018, no. 1 (28), pp. 88-101. In Rus.

14. Moiseeva A.P., Lankin V.G., Kondrateva I.V. Sotsialnaya inzheneriya $v$ kontekste transdistsiplinarnosti [Social engineering in the context of transdisciplinary] Tomsk, TPU Publ. house, 2012. $240 \mathrm{p}$.

15. Kowert W. The foreseeability of human artificial intelligence interactions. Texas law review, 2017, vol. 96, Iss. 1, pp. 181-204.

16. Lichtenthaler U. Substitute or Synthesis? The interplay between human and artificial intelligence. Researchtechnology management, 2018, vol. 61, Iss. 5, pp. 12-14.

17. Gobet F., Sala G. How artificial intelligence can help us understand human creativity. Frontiers in psychology, 2019, vol. 10, Article number 1401. DOI: 10.3389/fpsyg.2019.01401

18. Livingston S., Risse M. The future impact of artificial intelligence on humans and human rights. Ethics \& international affairs, 2019, vol. 33, Iss. 2, pp. 141-158.

19. Van Est R. Intimate technology: the battle for our body and behavior. 2014, 86 p. Available at: https://pure.tue.nl/ws/portalfiles/portal/3957297/608649605251186.pdf (accessed 22.10.2019).

20. Salles A., Evers K., Farisco M. Neuroethics and philosophy in responsible research and innovation: the case of the human brain project. Neuroethic, 2019, vol. 12, Iss. 2, pp. 201-211.

21. Lankin V.G. Mezhdu lichnostyu i professiey. Idei i problemy kompetentnostnogo podkhoda i aktiviziruyushchikh technologiy $\mathrm{v}$ vysshem obrazovanii [Between personality and profession. Ideas and challenges of the competency-based approach and activating technologies in higher education]. Tomsk State Pedagogical University Bulletin, 2012, Iss. 11 (126), pp. 9-14.

22. Yablonskyi A. Educational institution environment as the subject of humanitarian psychological expertise. Science and education, 2016, Iss. 11, pp. 85-90.

23. Lankin V.G. Modulnost obrazovaniya i tselostnost cheloveka: k kriteriyam ekspertizy gumanitarnykh praktik [Education modularity and human holism: to the criteria of humanitarian practice expertise]. Siberian Journal of Science, 2012, no. 1 (2), pp. 203-209. In Rus.

Received: 25 October 2019. 